\title{
Diminutive Reduplication in Government Phonology
}

\author{
Renée Lambert ${ }^{1}$ \\ Université Lumière Lyon 2
}

\section{Resumo}

As propriedades morfológicas e fonológicas da formação diminutiva por reduplicação são estudadas em função das hipóteses de Lowenstamm (1996, 1999) sobre a organização universal dos segmentos fonológicos e mais particularmente sobre a presença de um sítio morfológico ao inicial das palavras de categorias lexicais essenciais. É proposto que o sítio inicial seja o lugar da reduplicação diminutiva em francês. Factos do francês quebequeses bem como do antigo grego são apresentados sequidamente papa apoiar a hipótese segundo a qual as palavras são representadas universalmente por uma sequência estrita de consoantes e de vogais (CVCV...). 
This article deals with the diminutive formation by reduplication in French. These reduplications are typically

1 formed by the copy of the first consonant and the following vowel at the left of the base, for example fifille 'little girl', diminutive of fille 'girl', gueguerre 'squabble' (figurative) diminutive of guerre 'war'. The morphological and phonological properties of those formations will be studied following the hypotheses of Lowenstamm (1996, 1999) on the phonological constitution of words from major lexical categories (nouns, verbs). It will be shown that the properties of the diminutive formation in French are compatible with the three next statements: 1) the initial CV site proposed by Lowenstamm (1999) is the place of diminutive reduplications in French; 2) this type of reduplication is restricted to the size of the initial site, that is the first consonant and vowel only; and 3) this process of reduplication is productive. These hypotheses make predictions, first, that nouns beginning with an initial consonant cluster won't reduplicate, and second, that nouns semantically compatible with the diminutive interpretation will be able to form diminutives by reduplication. To assert these propositions, on one hand, we will present different types of diminutives obtained by reduplication in French and Canadian French, in order to show that this process is productive and that, effectively, consonant clusters do not reduplicate to form diminutives (at least, not with apparent implication of the initial site), and on the other hand, data from Canadian French and Ancient Greek will be analyzed to show that the universal organization of segments must be a strict consecution of consonants and vowels.

In the first section, we present the theory of government phonology and its new developments. The second section will be 
devoted to the morphological properties of the diminutive reduplication. The study of nouns beginning with a consonant cluster will be the object of section 3. Finally, we will end this paper on reduplications implying complex segments (aspirates, nasals).

\section{1. "ON THE BEGINNING OF THE WORDS"}

The study of Afroasiatic languages has greatly contributed to the progress of the theory of government phonology, especially on syllabic constituents. The work of Kaye, Lowenstamm \& Vergaud $(1985,1990)$ (henceforth KLV), among others, has shown that the organization of phonological segments in certain languages should be reconsidered according to the following principle.

(1) If a language $\mathrm{L}$ meets the following two conditions, then $\mathrm{L}$ has no closed syllables:

i. $\quad \mathrm{L}$ is a template language

ii. for any surface consonant cluster $\mathrm{C}_{\mathrm{i}} \mathrm{C}_{\mathrm{j}}$ displayed by $\mathrm{L}, \mathrm{L}$ also displays the mirror-image surface cluster $C_{j} C_{i}$.

(=(1), in Lowenstamm 1996)

According to (1), a language satisfying the conditions stated therein has no codas. Ensuing principles put forward by KLV, Lowenstamm (1996) has extended the analysis of languages with no initial consonantal restrictions to all languages ${ }^{2}$. He proposes that words of all languages are represented by a strict succession of consonants (C) and vowels (V), that is CVCVCV... Following this theory, there can't be any branching constituent. For example, a word like plafond 'ceiling' will be represented as in (2). Here, the empty vowel comprised between the $/ \mathrm{p} /$ and the $/ \mathrm{l} /$ is legitimized by the proper government of the phonetically realized vowel to its right ${ }^{3}$. 
(2)

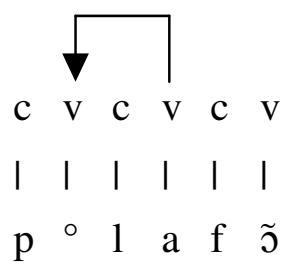

Furthermore, what has intrigued Lowenstamm in his 1999 paper are languages like French and English with no template phonology. Because of the proper government defined between vocalic constituents only, the prediction is that there will be no restrictions concerning consonants. Nevertheless, in French for example, we can only observe the sequences occlusive-liquid, but never the reverse liquid-occlusive ( $\mathrm{pl}$, *lp). Moreover, no language shows the sequence of decreasing sonority without showing the increasing sonority sequence * $\left(\mathrm{lb},{ }^{*} \mathrm{bl}\right)$. To give an explanation for those observations, Lowenstamm (1999) proposes that each word belonging to a major lexical category must be preceded by a CV site. This site is subject to the same requirements of phonological government as any empty vocalic position. Departing from this suggestion, Lowenstamm shows that the initial site in French and in languages having the same consonantal initial configurations (type 1) has to be properly governed, while in Arabic, for example, where the initial clusters are free (type 2), the site is not always governed. What are the implications of such a theory?

Since the initial site has to be properly governed in languages of type 1, we expect to find phonological arrangements allowing this proper government. This is what we observe in French, for example. The consonantal word initials are limited to two configurations: a simple one (e.g. [fãt] fente 'crack') or a complex one with increasing sonority (e.g. [bra] bras 'arm').

Lowenstamm (1999) adopts an idea put forward in Scheer (1996) suggesting that clusters formed by an occlusive and a liquid constitute a closed domain ${ }^{4}$. The result of the interaction between the two consonants is the possibility for the vowel captive by this 
relation to stay empty and to be transparent to proper government. The situations in (3a) and (3b) are then obtained.

(3)

a.
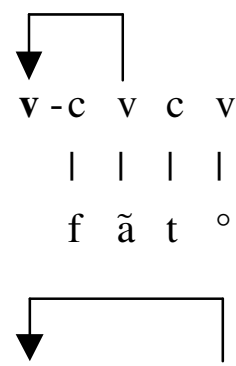

b. $\quad \begin{array}{ccccccc} & \mathbf{v} & -\mathrm{c} & \mathrm{v} & \mathrm{c} & \mathrm{v}\end{array}$

$$
\left.\begin{array}{llll}
\mid & \mid & \mid & \mid \\
{[b} & \circ & r
\end{array}\right] a
$$

As the CV initial theory stipulates that French has a site always properly governed, both preceding situations are the only ones possible. A word like *[rba] is ungrammatical in type 1 languages because it blocks the proper government of the initial site, as (4) shows.

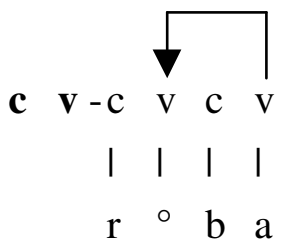

The representation in (4) can only belong to languages of type 2 , where the initial site may stay ungoverned. Also, both (3a) and (3b) can represent words from type 2 languages. It follows from the government of the initial $\mathrm{CV}$ that lexical material can become embedded in it. Lowenstamm (1999) gives the example of cliticization in French and Biblical Hebrew. We will present a brief summary of his argumentation here in order to show that there can be a clear manifestation of the initial site. For more details, the entire article should be consulted. 
Remember that French is a type 1 language and has an initial $\mathrm{CV}$ site that is always governed. The definite articles in French are reputed to cliticize onto the nouns they determine. This cliticization is expected to take place in the $\mathrm{CV}$ initial site because it is always properly governed. (5) and (6) show this process.

la fente 'the crack'

(5)

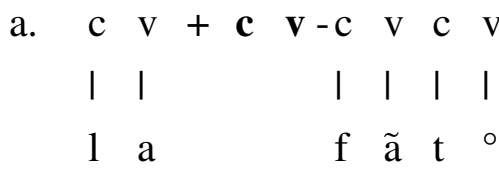

(6) a. c v + c v-c v c v

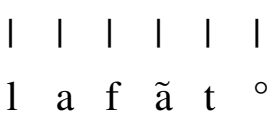

le bras 'the arm'

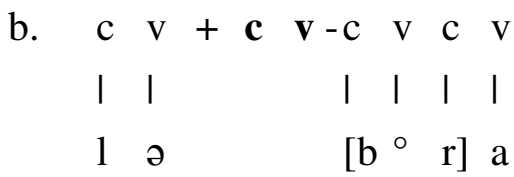

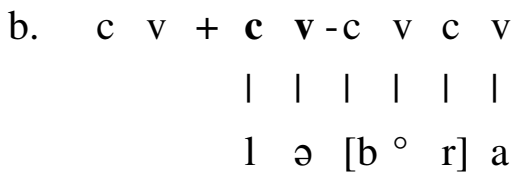

We can see in (5) that the clitic comes with its own CV, and in (6) that it deserts its CV to join the initial site of the noun on which it cliticizes. The CV left behind in (6) plays the role of the new initial site and is ready to host other lexical material.

For the type 2 languages, the behaviour is different. Those languages can manage an ungoverned initial site by phonological operations. Lowenstamm presents the case of the definite articles in front of some plurals of the segholate class in Biblical Hebrew. When the article $h a$ is prefixed to those nouns, the situation is similar to the one in (5) in the sense that the prefix has its own CV. 


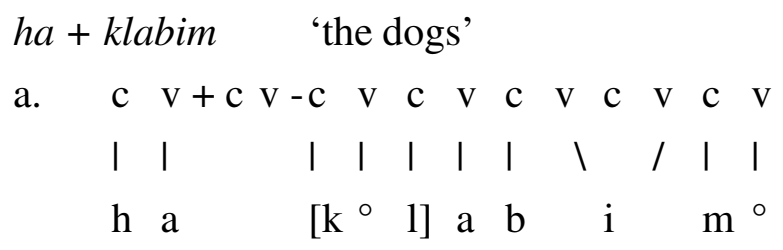

$h a+r q a \hbar m \quad$ 'the spices'

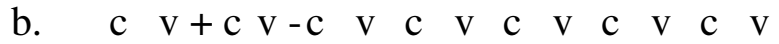

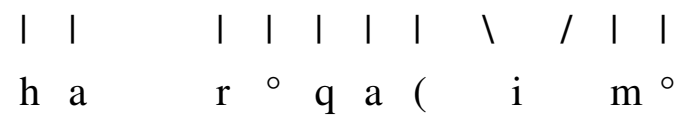

(from (26), in Lowenstamm 1999)

The status of the site is different between (7a) and (7b). In (7a), the initial CV site is properly governed by the vowel /a/ of the base. As we said before, lexical material can incorporate the site if and only if it is properly governed. We then expect to find the cliticized form * baklaßiim for (7a), where the ha simply becomes integrated into the initial site of the noun. But that is not the case. To understand what happens, it's advisable to look at the situation in (7b). The representation in (7b) shows that the initial site is ungoverned. The vowel /a/ of the base has to legitimize the empty vocalic position between the $/ \mathrm{r} /$ and the $/ \mathrm{q} /$ and therefore cannot legitimize the $\mathrm{CV}$ site. The result of this situation is the impossibility of the article to move into the site. We have then a case of an empty CV position that became part of the word. This CV cannot remain silent and has to undergo phonetic interpretation. Two strategies are available: compensatory lengthening or gemination. In (7b), the vowel /a/ of the prefix lengthened on the vocalic position of the initial site ${ }^{5}$. This is illustrated in (8b). The situation in (7a) can be resolved exactly like the one in (7b). Lowenstamm (1999) assumes the "Uniformity Convention", stipulating that for any given language, cliticization operates in uniform fashion with respect to the licensing status of the host site (p.12). So, Biblical Hebrew has cases of licensed initial site 
and cases of unlicensed initial site. The uniformity condition will make the CV site remain unlicensed throughout the language. What we observe for the cliticization in $(7 \mathrm{a})$ is the gemination of the first consonant $/ \mathrm{k} /$ of the noun to legitimize the $\mathrm{CV}$ site. This is illustrated in (8a).

(8)

\section{Gemination}

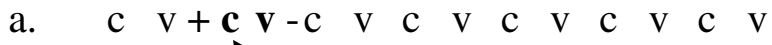

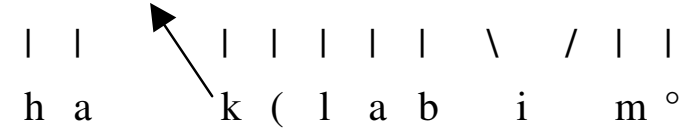

[hakkəlaßiim]

\section{Compensatory lengthening}

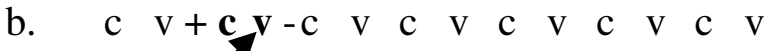

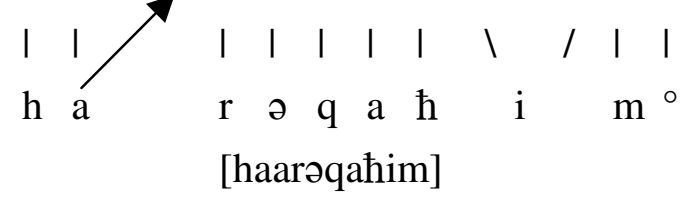

(= (28a) et (28b), in Lowenstamm 1999)

It emerges from our discussion that the differences between languages, as for clusters at the beginning of words, are explainable by the presence of an initial site. Whereas we can observe a clear phonological manifestation of the initial CV site in languages of type 2, like Arabic and Biblical Hebrew, that is not the case in languages of type 1 like French and English. We can therefore question the presence of this CV site in languages where it is always properly governed and where no phonological operations of gemination or compensatory lengthening are expected. How can we verify the presence or not of this site at the beginning of French nouns? In the next section, we will set forth facts from French allowing us to answer this question. 


\section{THE DIMINUTIVE REDUPLICATION}

Reduplication is a strategy of word formation used in most languages. This process implies that a part of a word or an entire word becomes affixed to itself to create another derived word. In French, we find cases of reduplication. There are two principal types: diminutives and onomatopoeias. We will leave the study of the latter for other research. For this paper, we will concentrate on diminutive (often figurative) formations by reduplication. Those nominal reduplications in French are characterized by the copy of the first consonant and the following vowel at the left of the base noun. Here are some examples in (9).

$\begin{array}{lll}\text { bébête } & \text { 'little animal' } & \text { from bête 'animal' } \\ \text { bibiche } & \text { 'little darling' } & \text { from biche 'doe, darling' } \\ \text { bobosse } & \text { 'hunchback' } & \text { from bosse 'hump' } \\ \text { fifille } & \text { 'little girl' } & \text { from fille 'girl' } \\ \text { gougoutte } & \text { 'little drop' } & \text { from goutte 'drop' } \\ \text { guéguerre } & \text { 'squabble' } & \text { from guerre 'war' } \\ \text { poupoule } & \text { 'chick (woman)' } & \text { from poule 'hen' } \\ \text { susucre } & \text { 'little sugar' } & \text { from sucre 'sugar' }\end{array}$

What are the exact functions assumed by this type of reduplication? First, we can attribute a morphological function to reduplication. Béchade (1992: 157-158) notices that we can legitimately consider different processes, other than derivation or composition, put forward by French to enrich its vocabulary, as integrating a general system of word formation. The words in (9) are then clear cases of new word formation. Moreover, morphological processes, unlike phonological processes, often compete, as shown by Bauer (2001). This is what we observe in French with the minimal pairs gougoutte 'little drop' / gouttelette 'droplet' and poupoule 'chick 
(woman)' / poulette 'lass', the suffix -ette being in French the usual diminutive suffix. Each word of these pairs constitutes nominal derivation bringing the diminutive meaning to a common base.

Morphological derivation comes with a principle of semantic compositionality, stipulating that the meaning of the derived word should be the sum of the meaning of the parts. In other words, we expect to find the meaning of the affix added to the meaning of the base in the semantics of the new word. When we look at nouns in (5), we see that this principle is respected. The noun gougoutte for example is the result of a derivation on the noun-based goutte 'drop'. The semantics of the complex noun obtained is petite goutte 'little drop', that is to say a combination of the meaning of the base and of the reduplicated affix. We can therefore conclude that there is a morphological role for this type of reduplication in French.

Second, can we provide a phonological function for reduplication? The answer is linked to the theoretical frame we adopt. Remember that Lowenstamm (1999) proposes that words of all major categories are preceded by an initial CV site. If we assume that the noun poule 'hen' for example has the representation in (10), the suggestion is that the initial CV is where the diminutive reduplication takes place in French.

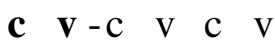

$$
\begin{aligned}
& \text { l I I I } \\
& \text { p } \quad \text { u } 1^{\circ}
\end{aligned}
$$

[pul] poule 'hen'

We propose, following Lowenstamm (2002), that the phonological content of the word is copied at the left and that there is an association of the segments to the site from left to right. This process is illustrated in (11). It explains why we don't have a form like*[pulpul], with the entire reduplication of the noun. The initial site narrows reduplication to the first consonant and the following vowel only. 
(11)

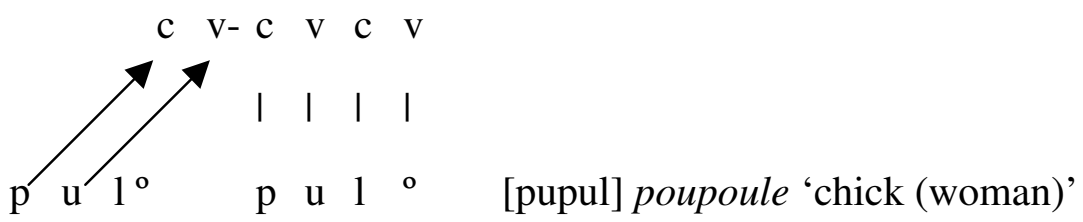

Since the initial site is argued to be present in front of all nouns, the prediction is that this process is productive. Productivity is defined by Bauer (2001) and Bybee (1985, 1996) (among others) as the probability for a pattern to be used to form new words. Bybee shows that the amount of semantic and/or phonological restrictions is inversely proportional to the chances for a process to be productive. In the case of diminutive reduplications, we have seen that there were very few semantic restrictions, in the sense that the meaning of the reduplicate nouns is predictable on the meaning of the base. Moreover, all the nouns in (9) are formed by the phonological reduplication of the first $\mathrm{CV}$ of the base. We can notice here that there are only few phonological restrictions. Thus, the process of reduplication presented in (11) has fulfilled all the conditions to be productive. The productivity of reduplication can be verified by the nouns in (12), all created on the model in (11).

\begin{tabular}{|c|c|}
\hline [ㅁobot] & from botte 'boot' \\
\hline [ kakart] & from carte 'card' \\
\hline [̌s $\varepsilon \check{s} \varepsilon z]$ & from chaise 'chair' \\
\hline œfœj] & from feuille 'sheet' \\
\hline$\varepsilon f \varepsilon s]$ & from fesse 'buttock' \\
\hline apat] & from patte 'leg' \\
\hline pport] & from porte 'door' \\
\hline$\varepsilon t \varepsilon t]$ & from tête 'head' \\
\hline
\end{tabular}

Of course, without a particular context, those words are hardly acceptable. Nevertheless, a French speaker will understand petite 
chaise 'little chair' if he hears [š๕šzz], and petite patte 'little leg' if he hears [papat]. For example, the noun *[patpat] for 'little leg', formed by the reduplication of the entire word could not be found. Since the semantic interpretation is predictable and since the reduplication is always restricted to the first open syllable in the creation of a new word, we can talk about a productive process. Productivity of the diminutive reduplication seems to be explained by the presence of an initial site.

Speaking in terms of a CV, the prediction that only the series Consonant-Vowel will be reduplicated is made. We have suggested in (11) that reduplication operates by an association from left to right of the copied phonological content in front of the base. Because the reduplication site has a restricted size, we predict that words beginning with a consonant cluster cannot reduplicate. This question will be the topic of the next section.

\section{THE CONSONANT CLUSTER CASE}

So far, we have seen that nouns beginning with a simple consonant could be derived in diminutives by the reduplication to the left of the base of the first consonant and the following vowel. What we have to verify now is if reduplication is possible in nouns beginning with a consonant cluster and if this reduplication observes the same rules as in the preceding cases.

In search of an answer, we presented a list of nouns with initial consonant clusters to a group of French speakers and we asked them to form their diminutives by reduplication on the model illustrated in (11). The results of this query are summarized in (13). They are divided in two strategies of derivation. The first one in (13a) consists of a complete reduplication of the base. The second one in (13b) presents a reduplicant that is the base without the final consonant. 
a. bras 'arm' : bras-bras clé 'key' : clé-clé fruit 'fruit': fruit-fruit pluie 'rain': pluie-pluie pois 'pea': pois-pois b. cloche 'bell': clo-cloche fleur 'flower': fleu-fleur glace 'ice' : gla-glace place 'place': pla-place plume 'feather' : plu-plume

The diminutive formation illustrated by the first strategy encounters another process existing in French. Indeed, we find a type of reduplication implying the complete copy of the base. Examples of this type of derivation are train-train 'routine' from train 'train' and trou-trou 'ornament with holes' from trou 'holes'. As these examples show, words with a complex initial consonants can be totally reduplicated. The difference with the ones in (13a) is semantic. In (13a), the semantic interpretation is clearly diminutive, which is not the case for the two latter examples: train-train does not mean little train. Nouns of the kind of train-train are not very numerous in French. In fact, this type of reduplication is not productive at all and is rather lexicalized.

We have to wonder if the process described in (13a) is another kind of reduplication, on the model of train-train and so totally different than the reduplication described in the preceding section, or if it falsifies our hypothesis on the role of the initial site or even its presence. Two kinds of analysis can be provided for the data in (13a). First, we can say that the initial CV site has nothing to do with reduplications and that those diminutive formations are simply formed by the copy at the left of the first open syllable. This analysis would also explain why we have [papat] and not *[patpat], for example. The problem is that in a theoretical framework like Government Phonology, consonants in a cluster are separated by an empty vocalic position. The implication here is that reduplications would be of variable size depending on the base. For illustrations, a word like patte 'leg' will reduplicate a CV, and a word like bras 'arm' will reduplicate a CVCV. We would prefer a process that operates in 
a uniform fashion. Second, we can say that reduplications in (13a) imply the reduplication of the entire word with its skeleton and the initial CV. We would then have an analysis similar to the one of traintrain. A support for this second analysis resides in the results in (13b). If we try to illustrate in (14) and (15) what is going on with the reduplication of the noun fleur 'flower', we see that the initial site plays a role.

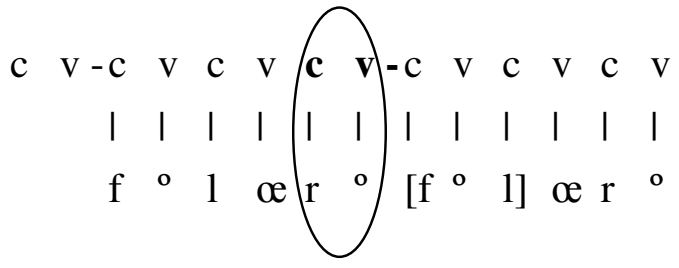

In (14), the noun fleur is reduplicated entirely. Since its initial $\mathrm{CV}$ site is properly governed, lexical material can be embedded in it. That is what happens in (15). The difference here is that the association is not from left to right and looks more like compounding. The copy is merged within the base via the initial CV site ${ }^{6}$. Government Phonology predicts the ungrammaticality of such a form. Scheer (2000) proposed that liquids have to be legitimized by a following realized vowel, except for the final position. In (15), the final liquid $/ \mathrm{r} /$ of the base is followed by an empty vocalic position but a final one. On the other hand, the consonant /r/ of the copy has now became a part of the word and has to be legitimized. This is not the case since the vocalic position following it is empty. Two actions can 
be envisaged to correct the situation: a schwa epenthesis in the vocalic position to legitimize the final $/ \mathrm{r} /$ of the copy or a deletion of the consonant $/ \mathrm{r} /$. The solution chosen is the most economical, the deletion of the final consonant of the copy.

It seems that the process involved in the diminutive formation in (13b) is the same as in (13a). This type of reduplication is not very productive in French, as we said earlier. In fact, very few reduplications of entire words bring a diminutive semanticism. It is rather used to mark onomatopoeias (ex. blabla 'smooth talk', froufrou 'rustle'). We will not discuss those cases further in this paper. What can be said about the reduplication described here is that it implies the entire copy of the base. At first sight, this strategy raises doubts about the hypothesis of an initial $\mathrm{CV}$ as the site of diminutive reduplication in French. Actually, on the surface, we observe the reduplication of the first two consonants and the following vowel. We have presented in (14) and (15) what we believe is the best analysis of those reduplications. The thing is, we still don't have any morphological use of the initial site with nouns beginning with a consonantal cluster. The two next sections are concerned with this fact.

\subsection{Diminutives in Canadian French}

Data from Canadian French are particularly interesting for the study of diminutive formation by reduplication. The same nouns that served for the experience resumed in (13) have been presented to speakers of Canadian French, with identical instructions, that is to form the diminutives of those nouns on the model (11). The results contrast with the ones obtained for the French speakers. If we take for example the noun pluie 'rain', remember in (13a) that the diminutive of this noun, pluie-pluie 'little rain (fig)', was formed by the entire reduplication of the base. This is not what happens for some of the Canadian French speakers. Rather, the initial CV site is used. 
The noun pluie is preceded by an initial CV. The reduplication, as we describe it in section 2, consists of a copy of the phonological content at the left of the base and of an association from left to right of the segments on the segmental positions $\mathrm{C}$ and $\mathrm{V}$ of the site. The prediction that we made is that if the initial site is used to form diminutives, forms like *[pluiplui] pluie-pluie or *[plyplui] plu-pluie or even *[pliplyi] pli-pluie are not expected. And this is the case for the majority of the Canadian French speakers questioned ${ }^{7}$. Instead, [pəplyi] is obtained, with the copy of the first consonant and a following schwa. So, we suggest that what is associated to the initial site corresponds to the first consonant $/ \mathrm{p} /$ and the empty vowel. The OCP (obligatory contour principle), preventing the two $/ \mathrm{p} /$ 's being adjacent, does the rest and forces the schwa epenthesis into the empty vocalic position. This is illustrated in (16).

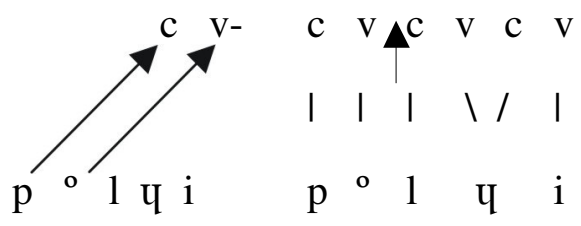

$\partial$

[pəplui]

In fact, cases of reduplication on words with a complex of initial consonants are extremely rare (at least, we haven't found many). Here is a small list of our findings in (17).

[bəbra] from bras 'arm'

[foflœr] from fleur 'flower'

[fofrui] from fruit 'fruit'

[gəglas] from glace 'ice'

[pəplyi] from pluie 'rain'

[pəplym] from plume 'feather' 
The data in (17) put forward a fact discussed in the first section, that is, that words of all languages are represented at a segmental level by a strict consecution of consonants (C) and vowels (V). The Canadian French data offer an answer. What is striking about the representation of the diminutive in (16) is the epenthesis of a schwa after the $/ \mathrm{p} /$. This would not be expected within a theoretical framework stipulating that the two consonants of increasing sonority form a complex onset. We would expect a situation where the other vocalic segments could come occupy the $\mathrm{V}$ position, for example the $/ \mathrm{q} /$ or $/ \mathrm{i} /$, as (18) shows.

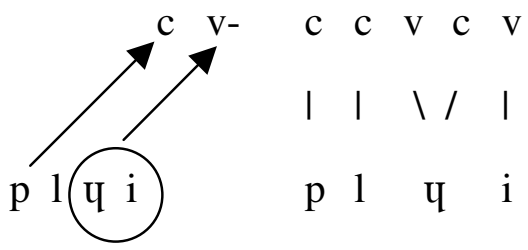

The glide / $\mathrm{q} /$ or the vowel / $/$ could associate with the vocalic position. We would then expect to find [pyplyi] or even [piplyi], but this is not the case for all our Canadian French informants. So, if we suppose that the word pluie contains an empty vocalic position between the $/ \mathrm{p} /$ and the $/ \mathrm{l} /$ and that reduplication implies the copy from left to right of the segments into the initial site, the $/ \mathrm{p} /$ and the empty vowel will be reduplicated. The schwa epenthesis is a consequence motivated independently of the reduplication process. From now on, we can assume that French is a strictly CVCV language.

In section 2, we have discussed the necessary conditions for a word formation process to be productive. Thus, we have seen that productivity was related to the semantic and phonological restrictions imposed by the model. Diminutive reduplication in nouns beginning with a consonant cluster is not productive and this is not surprising if we consider the situation described in (16). Of the entire phonological content of the base, only the first consonant is (really) 
reduplicate. The semantic value conveyed by the segments is partly lost in the process of reduplication. Moreover, we notice that there is an additional phonological restriction in (17) compared to reduplications in (9) and (12): the schwa epenthesis. Defining productivity as we did, it is clear that reduplications in nouns with complex consonantal initial are less expected. Nevertheless, the structure of these diminutives in French is the result of the presence of an initial CV site, at least in front of the nouns. In search for crosslinguistics data supporting our hypothesis concerning an initial site, Ancient Greek also shows interesting facts to be considered in this paper and will be the subject of the next section.

\subsection{Perfective formation in Ancient Greek}

A type of reduplication similar to the one describe previously operates in Ancient Greek to form the perfect. It consists of a reduplication in front of the base of the first consonant followed by the vowel /e/. Here are some examples in (19) drawn from Froli (2001: 47).
a. leluka
from luo 'to loose'
pepaideuka
from paideuo 'to educate'
b. $\begin{array}{r}\text { gegrap }^{\mathrm{h}} \mathrm{a} \\ \text { beblap }^{\mathrm{h}} \mathrm{a}\end{array}$
from grap $^{h} o$ 'to write'
from blapto 'to harm'

The data in (19a) are not surprising and look like those in (9). Lowenstamm (2002) proposes that the perfective formation in Ancient Greek is realized on the initial CV site, exactly like the French diminutives, with a vowel fixed by the perfective paradigm. The form leluka is then obtained instead of *luluka as we would expect if the vowel was also reduplicated. For the reduplications in (19b), the situation is similar to the one in (17). If we suppose that the initial $\mathrm{CV}$ is the site for perfective reduplication, consonant clusters won't be able to reduplicate. This is what is observed, represented in (20). 


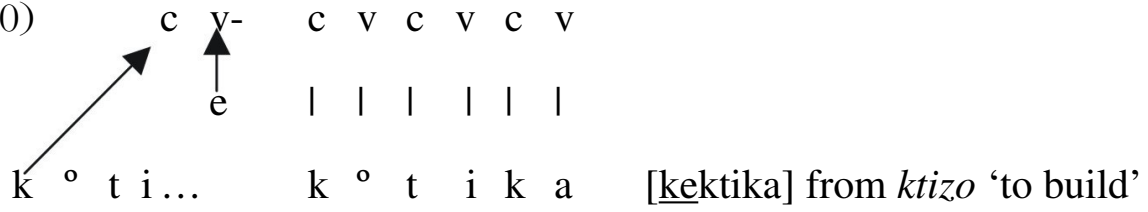

The difference between this process and (16) resides in the quality of the reduplicated vowel. As the vowel in (16) is realized by the epenthesis of a schwa in the empty vocalic position of the initial site, the vowel /e/ in (20) is constant and is ruled by the paradigm of the perfective formation.

If we resume what we tried to show until now, we can say that the presence of an initial CV site is motivated morphologically and has phonological consequences in reduplication. The illustration of the diminutive reduplications in French has shown that words can be reduplicated following a specific phonological pattern, that is to say by the copy at the left of the base of the first consonant and vowel. This pattern ensues from the initial $\mathrm{CV}$, where the segmental positions are restricted to a consonantal segment and a vocalic segment. In addition, the diminutives in Canadian French and the perfects in Ancient Greek also support this hypothesis. In the next section, we will try to bring out a recurrent question in the literature: the status of the phonological content of the aspirated and nasalized segments.

\section{ASPIRATES AND NASALS}

What we will try now is to reduplicate words containing aspirated segments (Ancient Greek) and nasalized segments (French). Those phonological items have been dealt with ambiguously in the literature. Some authors treat them as unique segments occupying a single segmental position, while others think that they are groups of segments occupying several skeletal positions. Diminutive reduplication offers a new way of analyzing aspirates and nasals, and thus clarifies this ambiguity, at least for Ancient Greek and French. 
In Ancient Greek, there are verbs containing an aspirated initial consonant. When the perfective reduplication is formed, the data in (21) are obtained, with the notable impossibility of having the aspiration reduplicated.

\section{(21) $\quad \mathrm{kek}^{\mathrm{h}}$ oreuka $\quad * \mathrm{k}^{\mathrm{h}} \mathrm{e}^{\mathrm{h}}$ oreuka from $k^{\mathrm{h}}$ оreuo 'to dance' kek ${ }^{\mathrm{h}}$ areka $\quad * \mathrm{k}^{\mathrm{h}} \mathrm{k}^{\mathrm{h}}$ areka from $k^{\mathrm{h}}$ airo 'to be delighted' tet ${ }^{\text {haumaka }} *$ thet $^{\text {h }}$ aumaka from $t^{\text {h }} a u m a d^{z} O$ 'to admire'}

The process of perfective formation by reduplication implies the copy of the first consonant and the insertion of the vowel /e/. If we analyze aspirates as only one phonological segment, we have to explain why the forms where the aspirated consonant is reduplicated are ungrammatical, by a rule of deletion of the aspiration, for example. Conversely, if we consider that the aspiration occupies its own segmental position, then no special rule is needed to explain why the occlusive only is reduplicated. These two stories are illustrated below.

(22) a.

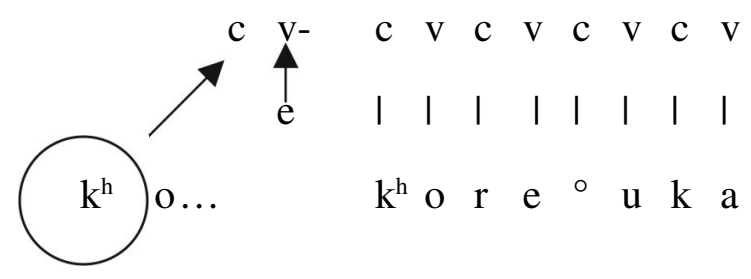

$/ \mathrm{k}^{\mathrm{h}} \mathrm{k}^{\mathrm{h}}$ oreuka/ $\rightarrow$ deletion rule $\rightarrow\left[\mathrm{kek}^{\mathrm{h}}\right.$ oreuka $]$

b.

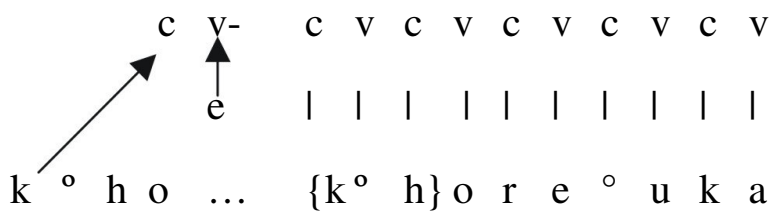

[kek ${ }^{\mathrm{h}}$ oreuka] 
In (22a), the only way to obtain the perfective form without the aspiration on the initial $\mathrm{C}$ is to add a rule, for example, of deletion, complicating the process. A more economical suggestion is made in (22b), which is to consider the aspiration independent of the occlusive. We get back there the reduplication process as we described it in (20).

The same reasoning can be made concerning nasal reduplications in Canadian French ${ }^{8}$. When a noun containing a nasal vowel is reduplicated to form the diminutive, the vowel is reduplicated without the nasality, as is shown by the examples in (23).

\begin{tabular}{|c|c|c|}
\hline [babãd] & *[bãbãd] & from bande 'group' \\
\hline [ $\underline{\mathrm{d}} \varepsilon \mathrm{d} \tilde{\varepsilon} \mathrm{d}]$ & $*[\mathrm{~d} \tilde{\varepsilon} \mathrm{d} \tilde{\varepsilon} \mathrm{d}]$ & from dinde 'turkey' \\
\hline [jajãb] & *[jãjãb] & from jambe 'leg' \\
\hline
\end{tabular}

Many works on nasality, notably Paradis \& Prunet (2000), discuss the number of segmental positions that nasal vowels must occupy. Data in (23) suggest that nasality is separate from the vowel it nasalizes, and so that nasals have to be considered as a

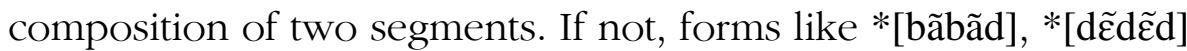
and *[jãjãb] would be expected. The two possible situations are illustrated in (24).

(24) a.

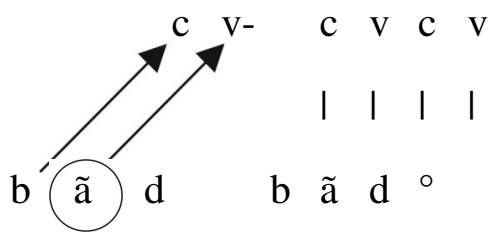

b.

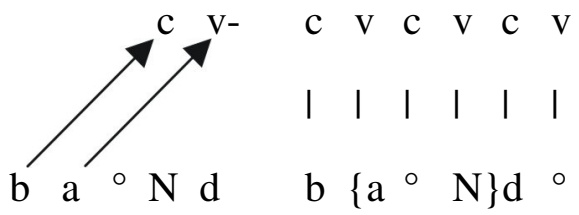


When nasality is represented as part of the vowel (situation (24a)), the consequence is that the vowel AND nasality are reduplicated in one segmental position. When nasality is independent of the vowel (situation (24b)), then only the vowel can be reduplicated. The simplest way to explain why nasality is not reduplicated in the diminutive formation in French is by stipulating an analysis like the one in (24b).

More research needs to be done in the area of the segmental complexity in order to determine the true composition of aspirates and nasals. However, data from Ancient Greek and French examined above present interesting characteristics to be considered in this study. On one hand, they provide an additional argument for the presence of an initial site in the size of a CV, and on the other hand, they show that it is better to give a bi-segmental status to the so-called complex segments like aspirated consonants and nasal vowels.

\section{CONCLUSION}

Many facts have been presented to support the hypothesis of a CV site at the beginning of words of all major categories. We have first seen that diminutive formation by reduplication in French is explainable by a morphophonological process occurring in the site. We have illustrated its productivity by showing that there were only very few semantic and phonological restrictions on this kind of reduplication. Moreover, the phonological pattern of the reduplication has been analyzed as being imputed to the initial CV site. We have then shown that the diminutives in French and the perfects in Ancient Greek were formed by the strict reduplication of the first consonant and the following vowel of the base.

Predictions were made concerning the non reduplication of consonant clusters. A particular process existing in Canadian French was presented in order to confirm this hypothesis. In the case of nouns beginning with a complex of initial consonants, only the first consonant is reduplicated, followed by a schwa epenthesis. We have 
concluded that consonants of a cluster must be separated by an empty vocalic position. Thus, this supports the suggestion of Lowenstamm (1996) that words should be universally represented by a strict succession of consonants and vowels.

The hypothesis of an initial CV site provides two major openings. The first is that it explains why consonant clusters cannot reduplicate. Indeed, we have seen in this paper that only the first consonant of a cluster is reduplicated, in Canadian French as in Ancient Greek. The second concerns the composition of aspirates and nasals. The impossibility of reduplication in the case of an aspirated consonant and a nasal vowel suggested that those segments were occupying more than one segmental position.

It is clear that this paper does not constitute the final word on this subject. However, it provides many leads for the treatment of the diminutive reduplication in French, as well as the perfective formation in Ancient Greek.

\section{NOTES}

${ }^{1}$ I am grateful to Jean Lowenstamm for discussions on the differences existing between France French and Canadian French and on theoretical issues dealt with in this paper.

This research was supported by a doctoral fellowship awarded by the Fonds de recherche sur la nature et les technologies from the government of Quebec.

${ }^{2}$ See also Bendjaballah (1995), Scheer (1996), Ségéral (1995).

${ }^{3}$ The reader is referred to Kaye, Lowenstamm \& Vergnaud $(1985,1990)$ for more information on Government Phonology.

${ }^{4}$ This argumentation is based on the analysis of Czech vowel/ $\varnothing$ alternations. Readers are asked to consult Scheer (1996) for demonstration of the complex situation in Czech.

5 This compensatory lengthening happens when the first consonant of the base resists gemination. (cf. Lowenstamm (1999: 12))

${ }^{6}$ We only suggest that a way of understanding the data in (13b) is to consider that the copy merged into the CV site, as we can imagine it does in compounding. Naturally, this proposition needs to be further explored, a thing we will not do here. 
${ }^{7}$ Some speakers of Canadian French produce a diminutive form where the first two consonants are reduplicated, followed by a schwa, for example [frofrui] for 'little fruit'. Those cases, not very representative, won't be dealt with in this paper.

${ }^{8}$ We have also run the test on French speakers, but since the nasals are less emphasized for them, we don't have a clear proof of the non reduplication of the nasalized vowel. Phonetic analysis should be made in order to obtain a precise answer.

\section{REFERENCES}

BAUER, L. Morphological Productivity. Cambridge: Cambridge University Press. 2001. (Cambridge Studies in Linguistics, n. 95)

BÉCHADE, H.-D. Phonétique et morphologie du français moderne et contemporain. Paris: Presses Universitaires de France, 1992.

BENDJABALLAH, S. Aspects du système verbal du berbère (kabyle). Doctoral dissertation - Université Paris 7, Paris, France, 1995.

BYBEE, J. L. Productivity, regularity and fusion: how language use affects the lexicon. In: SINGH, R. (éd.). Trubetzkoy Orphans: Proceedings of the Montreal Roundtable 'Morphonology: Contemporary Responses'. Amsterdam/Philadelphia: John Benjamins. 1996. p.247-269.

. Morphology: A Study of the Relations between Meaning and Form. Amsterdam/Philadelphie: John Benjamins. 1985.

FROLI, D. S. De la lénition des codas initiales en grec. Étude diachronique de la spirantisation grecque dans un cadre CVCV. DEA dissertation - Université de Nice, Nice, France, 2001.

KAYE, J.; LOWENSTAMM, J.; VERGNAUD, J.-R. Constituent structure and government in phonology. Phonology 7, n. 2, p.193-231, 1990.

. The internal structure of phonological elements: a theory of charm and government. Phonology Yearbook 2, p.305-328, 1985.

LOWENSTAMM, J. Paramétrisation du CV initial (le bébé et l'eau du bain), paper presented to the 4èmes Journées Internationales du GDR CNRS 1954 'Phonologies', Université Stendhal, Grenoble, France, 2002.

. The beginning of the word. In: RENISON, J.R.; KÜHNAMMER, K. (Ed.). Phonologica 1996: Syllables!?. The Hague: Thesus, 1999. p.153-166. 
LOWENSTAMM, J. CV as the only syllable type. In: DURAND, J.; LAKS, B. (Ed.). Current Trends in Phonology: Models and Methods. Salford: European Studies Research Institute, 1996. p.419-443.

PARADIS, C.; PRUNET, J.-F. Nasal Vowels as Two Segments: Evidence from Borrowings. Language, n.76, v. 2, p. 324-357, 2000.

SCHEER, T. De la localité, de la morphologie et de la phonologie en phonologie. HDR dissertation - Université de Nice, Nice, France, 2000.

. Une théorie de l'intéraction directe entre consonnes. Doctoral dissertation

- Université Paris 7, Paris, France, 1996.

SÉGÉRAL, P. Une théorie généralisée de l'apophonie. Doctoral dissertation Université Paris 7, Paris, France, 1995. 